\title{
Laboreal
}

Volume $12 \mathrm{~N}^{\circ} 2$ | 2016

Equipamentos de Proteção Individual II

\section{Uso situado de los EPP (equipos de protección personal) frente al riesgo biológico : ejemplo de un laboratorio seguro de contención de nivel 3}

O uso situado dos EPI (equipamentos de proteção individual) face ao risco biológico : Exemplo de um laboratório seguro de contenção de nível 3 L'usage situé des EPI face au risque biologique : L'exemple d'un laboratoire sécurisé de confinement type " $L 3$ ”

The situated use of PPE against biological risk : the example of a confined safety laboratory type " L3"

Irène Cottin, Gérard Vallery y Sofiane Dahak

\section{OpenEdition}

\section{Journals}

Edición electrónica

URL: https://journals.openedition.org/laboreal/2377

DOI: $10.4000 /$ laboreal.2377

ISSN: 1646-5237

Editor

Universidade do Porto

Referencia electrónica

Irène Cottin, Gérard Vallery y Sofiane Dahak, «Uso situado de los EPP (equipos de protección personal) frente al riesgo biológico : ejemplo de un laboratorio seguro de contención de nivel 3», Laboreal [En línea], Volume $12 \mathrm{~N}^{0} 2$ | 2016, Publicado el 01 diciembre 2016, consultado el 21 septiembre 2021. URL: http://journals.openedition.org/laboreal/2377 ; DOI: https://doi.org/10.4000/laboreal.2377

Este documento fue generado automáticamente el 21 septiembre 2021

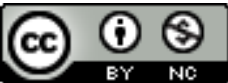

Laboreal está licenciado com uma Licença Creative Commons - Atribuição-NãoComercial 4.0 Internacional. 


\section{Uso situado de los EPP (equipos de protección personal) frente al riesgo biológico: ejemplo de un laboratorio seguro de contención de nivel 3}

O uso situado dos EPI (equipamentos de proteção individual) face ao risco biológico: Exemplo de um laboratório seguro de contenção de nível 3 L'usage situé des EPI face au risque biologique: L'exemple d'un laboratoire sécurisé de confinement type «L3» The situated use of PPE against biological risk: The example of a confined safety laboratory type «L3»

Irène Cottin, Gérard Vallery y Sofiane Dahak

NOTA DEL EDITOR

http://dx.doi.org/10.15667/laborealxii0216ic

Manuscrito recibido em: março/2016

Aceptado tras peritage: junho/2016

Quisiéramos agradecer a Florent Agis por la traducción del francés al español. 


\section{A) Introducción}

\section{1 - Contexto}

1 Según la Organización Mundial de la Salud, la tuberculosis es la segunda causa de mortalidad por enfermedad infecciosa en el mundo, luego de la infección por VIH, con 1,3 millones de muertes en 2010 (Antoine \& Che, 2012).

2 Aunque la incidencia [1] de la tuberculosis en Francia haya disminuido en las últimas décadas, existen importantes disparidades en el territorio. En particular, en el departamento de Seine Saint Denis, la tasa de declaración se mantuvo en 2010 a un nivel estable y elevado (Leporc, Carré \& Vandentorren, 2014). Es el departamento francés con la tasa de incidencia más elevada: mientras el promedio nacional era de 7,7 casos (por cada 100.000 habitantes), la Seine Saint Denis presentó un promedio de 27,5 casos. Algunos de sus municipios presentaron tasas de 35 a 58 casos por cada 100.000 habitantes entre los años 2010 y 2012 (Le Mab et al., 2012).

3 La tuberculosis es causada por una bacteria llamada bacilo de Koch (BK). Este bacilo se propaga por las vías aéreas, y es por consiguiente una enfermedad contagiosa. También es potencialmente mortal: sin tratamiento antibiótico, la forma pulmonar de la tuberculosis puede ser mortal en la mitad de los casos (Véziris, Jarlier \& Robert, 2012).

4 Además del número de personas infectadas, lo que más preocupa a la comunidad médica [2] es la evolución de la bacteria, en algunas regiones del mundo, hacia formas resistentes a los antibióticos. En Francia, algunos pacientes fueron diagnosticados con formas multiresistentes o ultraresistentes de la tuberculosis (el 5,5\% de los casos de tuberculosis en Seine Saint Denis, según Le Mab et al., 2012). La aparición de formas resistentes de la tuberculosis refuerza la necesidad de diagnosticar a los pacientes e identificar la cepa de la bacteria que portan. Por consiguiente, la identificación de los enfermos y su diagnóstico bacteriológico representan un desafío importante para la salud pública en el departamento de Seine Saint Denis. Se trata de curar a los enfermos y al mismo tiempo impedir que se propague la bacteria.

5 El artículo R-4421-3 del Código de Trabajo francés clasifica los agentes biológicos en cuatro grupos, según la importancia del riesgo de infección que representan. A cada grupo corresponde un nivel de precaución, para proteger el personal e impedir que se propague la enfermedad en el entorno.

6 El agente patógeno de la tuberculosis (BK) pertenece al grupo 3 (INRS, 1999). Según el artículo R-4421-3 del Código de Trabajo francés: «El grupo 3 incluye los agentes biológicos que puedan causar una enfermedad grave en el ser humano y presenten un serio peligro para los trabajadores. Su propagación a la colectividad es posible, pero existen generalmente una profilaxis o un tratamiento eficaces».

7 Los agentes biológicos del grupo 3 sólo pueden ser identificados en laboratorios de nivel «NSB3 [3] », o «L3». Se trata de un espacio cerrado: el aire que entra y sale es filtrado, todo el laboratorio está bajo presión negativa, el personal entra y sale por una esclusa doble, el material entra por una esclusa específica y sólo puede salir después de haber sido descontaminado, así como los residuos. Por consiguiente, este tipo de laboratorio debe consolidar su capacidad humana, técnica y organizacional, que analizaremos en la parte teórica de este documento. 


\section{2 - Origen de la solicitud y proyecto de investigación}

Puesto que la Seine Saint Denis no dispone de un BSL-3, un hospital público de la zona ha montado un proyecto de rehabilitación de sus locales para abrir uno. Además de las obras y adaptaciones técnicas, este proyecto representa un cambio importante para el personal.

Efectivamente, hasta entonces los técnicos de laboratorio sólo se ocupaban de las bacterias del grupo 2 [4]. Esta nueva actividad de investigación, cultivo e identificación de los BK provoca cambios en varios niveles, vinculados con el aumento del nivel de peligrosidad y las especificidades de las bacterias tratadas (los diferentes modos de transmisión, por ejemplo).

También se trata de una actividad diferente a nivel organizacional: tiene lugar en un espacio de trabajo confinado, implica prescripciones de seguridad muy altas, y requiere formaciones y habilitaciones para poder entrar en el laboratorio.

11 Por último, a nivel técnico, este cambio provoca numerosas modificaciones en el proceso de trabajo, en particular la descontaminación de las muestras mediante sosa antes de manipular las mismas, la creación de un sistema de seguimiento informatizado, por ejemplo un escaneo para cada muestra, pero también la eliminación y el rastreo de los residuos, la gestión de las existencias de material.

12 Para gestionar este gran proyecto (la proyección anual siendo de 15.000 muestras a analizar), se creó un comité directivo. Sus miembros así como el CHSCT (Comité de Higiene, Seguridad y Condiciones de Trabajo), siendo conscientes de los riesgos para el personal, han solicitado ser acompañados desde las fases iniciales del proceso para prevenir les riesgos profesionales.

13 Por iniciativa del director del proyecto «prevención» del hospital, dicha solicitud se convirtió en un proyecto de investigación-acción a tiempo parcial, escalonado en tres años (2014-2016), gracias a una financiación del FNP [5].

14 Este artículo se enfoca en una parte de la investigación, destinada a comprender por qué los operadores utilizan, modifican o descuidan el uso de los EPP en la práctica. La comprensión de estas razones conduce a proponer acciones para favorecer el uso "adecuado" de los EPP.

Para contestar a esta interrogación, emplearemos dos conceptos teóricos: las percepciones de riesgo y la actividad laboral, a nivel individual y colectivo.

\section{B) Marco teórico}

16 Se puede definir el riesgo como la probabilidad de un efecto perjudicial para la salud y la gravedad de ese efecto, como consecuencia de un factor de peligro (Setbon, 2004). En las situaciones laborales que incluyen peligros, tenemos por un lado a los trabajadores cuya salud se encuentra directamente amenazada, y por otro lado al empleador, el cual es responsable de asegurar su seguridad efectiva. Los técnicos de laboratorio manipulan muestras y cultivos que contienen bacterias peligrosas, como el BK. No es posible eliminar ese factor de peligrosidad, puesto que la finalidad de su trabajo es precisamente identificar dichas bacterias. Por consiguiente, existe un riesgo de contaminación identificado en todas las etapas en las cuales se manipula esa bacteria. En este caso, la prevención consiste en aplicar las medidas organizacionales y técnicas 
necesarias para evitar la contaminación de los operadores y del entorno. Por eso, el uso de los EPP desempeña un papel clave en esta actividad laboral. recordar los vínculos entre la percepción de riesgo y los comportamientos de prevención de los individuos. Se tratará de comprender cómo las representaciones individuales y colectivas pueden orientar el cumplimiento de las instrucciones de prevención, en particular el uso de los EPP.

20 - Por fin, veremos cómo esta relación con el riesgo se incluye en la actividad laboral: por un lado, las prescripciones de seguridad orientan la actividad del operador (seguridad reglada o regulada); por otro lado, los operadores desarrollan y aplican regulaciones frente a las situaciones de riesgo que encuentran (seguridad gestionada).

\section{1 - La prescripción organizacional}

21 El código de trabajo francés obliga al empleador a tomar las medidas necesarias para proteger la salud y garantizar la seguridad de sus empleados. Así, al no poder evitarse un factor de riesgo identificado, el empleador debe implementar una prevención planificada. Existe una orden de prioridad con respecto a estos principios de prevención, desde la eliminación del factor de riesgo hasta la implementación de medidas de protección a nivel colectivo y, como último recurso, individual (Artículo L4121-2).

22 Así, la prevención en un BSL-3 supone recursos humanos, técnicos y materiales (CNRS 2014) adaptados a la peligrosidad de los elementos manipulados:

- Los recursos humanos incluyen la información a los operadores y su formación sobre el riesgo biológico, las instrucciones de seguridad, el uso de protecciones colectivas e individuales, así como sobre las precauciones necesarias para evitar exponerse a riesgos y prevenir los accidentes. Se trata también de implementar una vigilancia médica específica que permita al médico laboral determinar la compatibilidad entre el estado de salud del operador y las particularidades del puesto de trabajo que éste ocupa.

- Los recursos técnicos están relacionados con la dimensión material de la prevención: la contención del laboratorio, el uso de campanas extractoras (cabinas de seguridad microbiológica o CSM), la selección de los equipos de protección personal.

- Los recursos organizacionales consisten en cuatro puntos:

- Las medidas específicas como la limpieza y el mantenimiento de los locales, el mantenimiento de los equipos y del material por las personas habilitadas,

- Las buenas prácticas de laboratorio (las prescripciones organizacionales) tendientes a evitar la creación de aerosoles, mediante protocolos de manipulación,

- Las operaciones de limpieza, desinfección, antisepsia y esterilización,

- La gestión de los residuos biológicos para evitar que los gérmenes peligrosos se propaguen fuera de los recintos. 

enriquece los modelos de regulación: cambios en la manera de buscar y dar sentido a las informaciones sobre el entorno, mayor capacidad de anticipación de las perturbaciones, toma de conciencia creciente de las propiedades de los objetos en el trabajo y de su propia actividad, y una reestructuración de las representaciones de las características superficiales hacia las características funcionales (Weill-Fassina, 2010).

31 A medida que el individuo se ve confrontado a distintas situaciones de riesgo, su experiencia le permite actuar de manera adecuada. Así, el comportamiento de un individuo relativo a un riesgo dependería de tres factores principales, procedentes del 
"health belief model". La amenaza percibida vinculada a su percepción del peligro, y su propia vulnerabilidad.

- La motivación para protegerse, que depende de la eficacia percibida de la medida de prevención.

- La aceptabilidad del costo subjetivo del seguimiento de esta recomendación (esfuerzos realizados, obstáculos).

Estos distintos elementos son integrados por el individuo en forma de una percepción de riesgo, que influye en su decisión conductual e individual, en relación con la prescripción de prevención.

Se ha demostrado en una población de enfermeras que el uso de ciertos equipos no era sistemático y dependía de la percepción del riesgo real en la práctica (Davillerd, 2001). Por ejemplo, se ha mostrado que el conocimiento del estado de un paciente respecto al VIH llevaba a los operadores a percibir una inyección como una acción más arriesgada para ellos mismos, y por lo tanto a utilizar guantes para una mayor protección.

Sin embargo, estos factores individuales no deben ocultar la influencia de los factores sociales, cuando un individuo debe decidir cómo comportarse frente a un riesgo.

\subsection{La influencia de la percepción social de riesgo}

Permanece una dimensión subjetiva y social con respecto a un riesgo. Efectivamente, el riesgo objetivo no existe en sí mismo: es una construcción social, relativa a consideraciones históricas, culturales, sociales (Le Breton, 2012). El concepto de riesgo depende de la percepción y de los valores de los individuos que examinan las distintas situaciones (Cadet et Kouabénan, 2005). Sería útil comprender dicha percepción para lograr más seguridad, en particular en los lugares de trabajo (Inouye, 2014).

La corriente de las percepciones sociales se centra especialmente en la importancia de la construcción colectiva del significado dado a un objeto social. Esta corriente estudia la construcción, el contenido, la función y la evolución de percepciones compartidas por los miembros de un grupo, a propósito de un objeto social. Estas percepciones tienen cuatro funciones: una función de saber, una función identitaria, una función de orientación y una función de justificación de las acciones (Abric, 1994).

En el ámbito laboral, la función de saber de las percepciones está estrechamente vinculada a la profesión: los saberes, procedentes de los conocimientos adquiridos a través de la formación inicial, son uno de los elementos constitutivos de las percepciones. La función identitaria de las percepciones está vinculada al objeto de trabajo compartido; por ejemplo, el hecho de trabajar en contacto con el riesgo biológico forma parte de la identidad de los técnicos. Este aspecto de la percepción une los unos con los otros en el seno del grupo, orienta sus comportamientos y hace más previsibles los comportamientos de los colegas. Eso determina un sistema de expectativas a través de la función de orientación de las percepciones: un técnico espera que sus colegas sepan en qué etapas de la actividad aparece un riesgo elevado, y por tanto actúen en consecuencia para evitar que ellos o los miembros del grupo corran peligro. Por ejemplo, un técnico debe saber que la manipulación de cultivos positivos es mucho más peligrosa que la manipulación de muestras. La función de justificación de las acciones vinculadas a las percepciones puede movilizarse en el análisis de la actividad: proporciona indicaciones sobre la lógica subjetiva en que se basan las acciones de los operadores. 
38 Así, el análisis de las precepciones puede proporcionar elementos de comprensión sobre la relación entre la construcción colectiva de una percepción y las decisiones resultantes, en particular en materia de comportamiento preventivo: "Debido a las interacciones y al intercambio de experiencias, los individuos que son miembros del mismo grupo o de la misma comunidad acaban elaborando una cultura de riesgo común." (Cadet et Kouabénan, 2005, p.18). Por consiguiente, los determinantes sociales que intervienen en la percepción de riesgo pueden estudiarse a nivel de un grupo, como los colectivos profesionales. Así, la pertenencia a un grupo profesional determinado puede proporcionar informaciones sobre la manera en que se percibe y se evalúa un riesgo profesional. Dicha evaluación resulta en un comportamiento más o menos adecuado a la prescripción inicial de prevención.

Por ejemplo, el hecho de percibir colectivamente los EPP como una ventaja para la salud puede favorecer el uso de los mismos (Davillerd, 2001). Los operadores citados por este autor consideran los EPP como "un escudo protector, una barrera contra las infecciones, la contaminación y los innumerables gérmenes", (p.6) y hasta los ven como una protección contra la suciedad. Esta visión positiva sobre los EPP también puede aplicarse a las herramientas o procedimientos de protección: los contenedores utilizados para evitar que uno se pinche con una aguja usada, las prácticas de lavado de manos para limitar la contaminación del personal o de los pacientes.

Por consiguiente, parece que una percepción de la utilidad de los EPP contribuye a motivar a los operadores para el uso de los mismos, a pesar del costo subjetivo resultante. Así, además de su propia individualidad, la dimensión social de los individuos se moviliza en su manera de percibir un riesgo. En otros términos, su percepción individual de un riesgo se ve influenciada por el entorno social en el cual están integrados.

41 En situación de trabajo, las prescripciones de seguridad se enfrentan a las percepciones (individuales y sociales), lo que conduce a distintas acciones:

- Una coherencia entre la percepción y la prescripción, y por tanto la aplicación de esta última: uso de los EPP, seguimiento del protocolo.

- Incoherencia entre la percepción y la prescripción: esta última puede ser modificada o infringida.

- Cuando la prescripción no determina precisamente la acción que hay que realizar, la percepción de los operadores, relativa a la probabilidad de que aparezca un riesgo, es la que va a guiar sus acciones (frecuencia con la que se cambian los guantes, decisión de cambiar de soporte o pulverizar un líquido descontaminante, decisión de reutilizar un EPP o tirarlo...).

42 Así, el cumplimiento o incumplimiento de la prescripción frente a los riesgos puede entenderse como el resultado de una interacción entre la percepción social y la percepción individual, ambas siendo vinculadas a unos determinantes situacionales. El uso de los EPP está situado y, en este marco, parece necesario centrarse en estos determinantes situacionales de la actividad laboral.

\section{3 - El vínculo entre la prescripción de prevención y los determinantes de la actividad}

Para comprender los vínculos entre las prescripciones de prevención y el trabajo efectivo, parece inevitable movilizar el concepto de la actividad, la cual se sitúa en el 
centro de la diferencia entre la tarea prescrita y el trabajo efectivo. En términos de seguridad, la tarea prescrita se refiere al sistema de seguridad tal como lo define el empleador: se trata de los riesgos "objetivos" que pueden provocar accidentes (WeillFassina, 2010). Como se describe anteriormente, esta dimensión prescrita de la seguridad implica el uso de las herramientas, incluso los EPP, y el cumplimiento de las normas de seguridad en la situación prevista por los prescriptores.

Sin embargo, desde el punto de vista del operador existe también un riesgo "subjetivo". Frente a dicho riesgo subjetivo, la prescripción puede ser inadecuada.

Efectivamente, las prescripciones pueden representar recursos o limitaciones para la prevención (Caroly, Simonet \& Vézina, 2015). Las prescripciones de prevención eficaces deben tener en cuenta los distintos determinantes (físico, cognitivo, subjetivo, social) del trabajo efectivo. En otros términos, centrándose exclusivamente en la identificación de la conformidad o de la desviación de un comportamiento con respecto a la prescripción, sin tener en cuenta el contexto en el que se manifieste, los riesgos resultantes de la situación de trabajo y la variabilidad humana, se puede ocultar la comprensión global de los comportamientos frente al riesgo, en particular el uso de los EPP. Esto llevaría a establecer prescripciones de seguridad que quizás no serían eficaces en cada situación, por no estar adaptadas a la actividad.

Entre las causas de inadaptación, en primer lugar hay que considerar los aspectos relativos a las cualidades intrínsecas de los EPP. Estos aspectos intrínsecos de los EPP, teniendo en cuenta las características del operador que los usa, pueden ayudar a comprender los comportamientos estratégicos relativos a un uso adecuado o inadecuado.

\subsection{La incomodidad de los EPP (dimensión técnica de los EPP)}

El hecho de no usar sistemáticamente los equipos de protección se basa en razones "objetivas" en relación con las dificultades reales encontradas por los operadores. El conflicto entre el criterio de protección y el de comodidad para el usuario parece inevitable (Davillerd, 2001; Garrigou \& Le Frious, 2015). Existe entonces una paradoja: por un lado, no tiene sentido usar un equipo cómodo pero poco eficaz en términos de protección; por otro lado, un equipo que ofrece una buena protección puede perturbar el buen desarrollo de la actividad por ser incómodo. Así, los operadores señalan que los guantes les molestan para desempeñar su trabajo: en particular, los guantes les impiden recoger informaciones sensoriales y provocan una "ausencia de la sensación de tacto, de sensibilidad" (p.6). Pues bien, esta sensación aparece como indispensable para algunas tareas ("allíse pincha con el tacto, no con la vista"), y puede entrar en conflicto con algunos criterios del "trabajo bien hecho" (Clot, 2010) al reducir el contacto humano. En este sentido, los EPP pueden resultar incompatibles con el trabajo efectivo.

Con la resolución de este conflicto de criterios se podría, en primer lugar, beneficiar de la mejora del material; pero los estudios técnicos, que son indispensables, también requieren un enfoque ergonómico, teniendo en cuenta la prominencia de la prescripción de seguridad entre todas las prescripciones: los objetivos de producción, el uso de las herramientas, el espacio de trabajo, es decir "la diferencia entre la seguridad prescrita y la seguridad efectiva en distintas situaciones" (Davillerd, 2001, p. 2). 
49 Por consiguiente, se debe tener en cuenta que la lógica de los diseñadores y la de los usuarios pueden ser diferentes: si los primeros piensan en términos de aceptabilidad intrínseca del EPP, los segundos razonan en términos de contextos de uso.

Así, las razones que llevan a los operadores a aceptar, rechazar o modular el uso de los EPP son en parte intrínsecas a los EPP; por eso los EPP pueden ser considerados como recursos o limitaciones para el operador o la actividad. El aspecto más importante se encuentra por consiguiente en el vínculo entre los EPP y la actividad laboral.

\subsection{Trabajo y actividad}

51 Dado que el trabajo se inscribe en un contexto organizacional, la manera de realizar el trabajo depende en primer lugar de la prescripción resultante de la organización. En otros términos, la prescripción organizacional (de seguridad) determina la tarea que el operador tiene que realizar.

52 Estas prescripciones de seguridad representan la "seguridad reglada", que tiene por objeto controlar los riesgos mediante reglas, procedimientos, y la definición de buenas prácticas. Estas prescripciones proceden de las evaluaciones de riesgos y son asociadas a una gerencia que asegura el cumplimiento de la reglas (Daniellou, Simard \& Boissières 2010; Nascimento, Cuvelier, Mollo, Dicioccio \& Falzon, 2013).

53 Así pues, trabajar no es simplemente aplicar la prescripción. Trabajar supone someter al debate, ordenar y priorizar una variedad de fuentes de prescripciones que pueden ser contradictorias; por lo tanto, trabajar es aceptar que todas estas prescripciones no sean siempre cumplidas (Daniellou, 2002). Entonces, trabajar significa ver las percepciones y las prescripciones de prevención enfrentarse en un contexto determinado, lo que puede provocar conflictos. Dicho de otra manera, la actividad es lo que el operador pone en juego para realizar una tarea: incluye la gestión inteligente y las estrategias que el operador aplica efectivamente para alcanzar su objetivo en una situación determinada: "la acción no sólo está vinculada a unos objetivos; se construye en situación real, no se reduce a la simple ejecución de reglas y depende estrechamente de las circunstancias locales, materiales y sociales que la determinan y le dan sentido" (Valléry, 2004, p. 123). La actividad real es el medio a través del cual el operador se ajusta a las prescripciones de una tarea determinada dentro de una organización, teniendo en cuenta sus percepciones individuales y sociales, así como los imprevistos.

Efectivamente, la situación de trabajo puede definirse como la interacción entre un individuo y la tarea (Hoc, Amalberti, Cellier \& Grosjean, 2004). Los operadores deben adaptar sus modos operativos para garantizar que se logre el resultado deseado, a pesar de las variaciones de situaciones y de su propio estado de salud. Estas regulaciones tienen por objeto la realización de las tareas, persiguiendo varios objetivos simultáneamente: el rendimiento (en términos de calidad, cantidad y seguridad), evitar los efectos negativos sobre el bienestar (por ejemplo, evitando fatigarse), y la búsqueda de beneficios como la sensación del trabajo bien hecho, el desarrollo de competencias (Daniellou, Simard \& Boissières, 2010).

55 Entonces, los operadores van a reinterpretar las tareas prescritas y adaptarse de la mejor manera posible, dependiendo de los recursos de la situación. En las situaciones de riego, esta reinterpretación de las situaciones y las regulaciones establecidas explican en parte la diferencia entre la prescripción de prevención y su aplicación efectiva. 
56 Frente a esta diferencia, los operadores desarrollan estrategias individuales y estrategias colectivas para responder a los imprevistos, a las variabilidades así como a las exigencias de productividad. Las estrategias pueden ser redundantes, complementarias o contrarias a las prescripciones de seguridad (Vidal-Gomel, 2002).

\subsection{Las estrategias colectivas de regulación}

57 Frente a las limitaciones de la situación, los operadores, de manera colectiva, pueden readaptar las reglas o elaborar nuevas, en un trabajo de "reorganización de la tarea" (Clot, 2000). Esto produce nuevas prescripciones y nuevas percepciones relativas a los objetos del trabajo. El grupo se esfuerza por reorganizar el trabajo para regular la tensión resultante del conflicto de criterios.

58 Una de las estrategias de regulación utilizadas por los empleados para responder a la diferencia entre lo prescrito y lo efectivo es la cooperación. La cooperación es una actividad colectiva que lleva a los operadores a trabajar juntos, sobre el mismo objeto y con el mismo objetivo proximal (De la Garza, 1995). La cooperación implica un reparto del trabajo que se realiza según la disponibilidad de los diferentes operadores (sus conocimientos, sus competencias y su estado de salud) y según las exigencias de la situación de trabajo (De la Garza \& Weill-Fassina, 2000). Lleva al operador a integrar las expectativas de sus colegas y a analizar los comportamientos de cada uno.

59 En el marco de la gestión de riesgos, el grupo se ve implicado en la seguridad "gestionada". Se trata de la anticipación, de la percepción y de la forma en la que los operadores responden a los fallos imprevistos por la organización. Esta gestión en situación de la seguridad se basa en los conocimientos de los operadores y sus iniciativas; necesita un funcionamiento organizacional y una gerencia que favorezcan dicha cooperación, teniendo en cuenta la realidad de las situaciones (Daniellou, Simard \& Boissières, 2010). Sin embargo, aún dentro del grupo permanece una parte de la actividad que depende del individuo y de sus percepciones.

\subsection{Adaptación recíproca de la actividad y del uso de los EPP}

La introducción de un nuevo equipo de protección o de nuevos procedimientos de seguridad puede, paradójicamente, provocar la reticencia de los operadores por las dificultades de adaptación y la complejidad de las tareas resultantes. Los operadores pueden tener dificultades para aprender nuevos gestos, desaprender e inhibir los automatismos, para adaptarse a las exigencias del EPP. Éste puede cambiar radicalmente las percepciones habituales, e incluso provocar nuevos miedos paradójicos: así, Davillerd (2001) cita "el miedo a ser contaminado con un nuevo gesto que uno no domina" (p.13). También, a veces los operadores piensan tomar más riesgos cuando no conocen el equipo. Por otra parte, la situación en la cual se desarrolla la actividad puede llevar a los operadores a tomar decisiones dependiendo de distintos criterios de prioridad: así, en ciertos casos de emergencia, ellos admiten que su propia protección no es necesariamente prioritaria, cuando sí lo sería en condiciones normales.

61 El tipo de tarea a realizar determina también el uso del EPP (los guantes serían preferidos para el baño de un paciente, pero de empleo muy variable para poner inyecciones), así como la confianza en la eficiencia de los EPP respecto al objetivo de los 
mismos: en cuanto a las inyecciones, cierto escepticismo existe respecto al uso de los guantes, que "no impedirán que la aguja los perfore" (Davillerd, 2001, p.6).

También parece que los operadores tienen en cuenta unos determinantes internos, relativos a la percepción de su propia vulnerabilidad (como el hecho de tener las manos arruinadas), y que su percepción de riesgos respecto al paciente influye también en su decisión de usar o no los EPP. Por un lado, se trata de protegerse: un paciente sospechoso de portar la tuberculosis lleva a los operadores a ponerse una mascarilla. Por otro lado, en el caso de un paciente débil o inmunodeficiente, tienen que emplear precauciones adicionales para protegerle. Así, la mascarilla en este caso sería considerada como "una protección de doble acción" (Davillerd, 2001, p.8).

En resumen, las estrategias aplicadas individualmente o colectivamente en la actividad tienen por objeto compensar o controlar los conflictos que pueden existir entre las percepciones y las prescripciones de prevención. Las estrategias desarrolladas por los operadores dependen de la prescripción de prevención, y ésta se enfrenta a la actividad efectiva. A veces, estas estrategias resultan de la prescripción de seguridad original.

Para comprender las razones de los operadores para seguir o no las prescripciones de seguridad, hay que considerar en qué medida dichas prescripciones, en particular las relativas a los EPP, tienen coherencia o no con la actividad laboral efectiva.

Así, el problema no se reduce únicamente a intentar comprender por qué los operadores no siguen estrictamente las normas de protección o no usan sistemáticamente los EPP impuestos. Las conclusiones anteriores llevan a considerar las situaciones de trabajo peligrosas teniendo en cuenta todos los aspectos que las determinan, en particular los aspectos técnicos, organizacionales y contextuales, subjetivos y colectivos. Efectivamente, el hecho de no utilizar un EPP específico no resume la actitud del operador frente a la gestión de la seguridad en situación de trabajo; no significa que actúan con negligencia o toman riesgos. Por eso, parece interesante considerar las percepciones y los comportamientos de los operadores respecto a los EPP como una ocasión para reflexionar colectivamente sobre la manera en que la prescripción de prevención se incorpora en el conjunto de los determinantes de la actividad.

Si fuera posible debatir de manera transparente sobre el conflicto de criterios entre la prescripción de seguridad, las exigencias de la actividad y las percepciones de los operadores, eso podría llevar a una mejor aplicación de las prescripciones de prevención.

\section{C) Preguntas de investigación}

67 Habida cuenta de estos elementos, las preguntas siguientes van a orientar el análisis del uso de los EPP:

1. ¿Qué funciones ocupan las percepciones de riesgo en el uso de los EPP?

2. ¿De qué manera las percepciones colectivas transforman el seguimiento de las prescripciones de seguridad?

3. ¿Cuáles son los impactos de los determinantes de la actividad sobre el uso de los EPP? ¿Cómo conciliar el uso de un EPP y las exigencias de la actividad? 


\section{D) Población}

En esta investigación se examina una población de quince técnicos de laboratorio. Diez trabajan en un BSL-2, y cinco en un BSL-3.

El análisis presentado aquí se centra en particular en los cinco operadores del BSL-3. Se trata de tres hombres y dos mujeres, de 26 a 51 años de edad.

Tres operadores tienen una experiencia de menos de cinco años como técnicos de laboratorio. Ninguno de ellos había trabajado antes en un BSL-3. Dos de ellos fueron contratados externamente para trabajar específicamente en el BSL-3, y el tercero era uno de los técnicos del BSL-2. Dos operadores tienen más de cinco años de experiencia. Ambos fueron contratados externamente, y sólo uno tenía varios años de experiencia en un BSL-3.

\section{E) Metodología}

11 La recopilación de datos relativa a la gestión del riesgo biológico en la actividad laboral se desarrolló en dos etapas. Luego se implementó una fase de acciones.

En primer lugar, se trató de determinar las percepciones y creencias de los operadores respecto al riesgo que corren a través de su actividad laboral. En segundo lugar, se trató de comprender el vínculo entre las exigencias de la actividad y las consignas de seguridad, especialmente sobre el uso efectivo de los EPP para los operadores que trabajan en los BSL-2 y 3.

3 Basándose en esos resultados, se crearon grupos de trabajo formados por los técnicos y los biólogos del BSL-3: su objetivo era transformar las situaciones de trabajo, mientras eran objeto de un análisis reflexivo.

74 Efectivamente, el enfoque ergonómico implica una relación dialéctica (Leplat, 2008) entre la comprensión y la acción: el análisis de la actividad permite transformar las situaciones laborales a fin de mejorarlas. A su vez, la acción sobre las situaciones laborales permite aumentar la comprensión del trabajo.

5 Estas fases de recopilación de datos y de acción sobre la situación laboral han necesitado una metodología cualitativa, combinando entrevistas, observaciones y la autoconfrontación de los grupos de trabajo.

\section{1 -Entrevistas individuales}

Unas entrevistas semiestructuradas fueron realizadas a los técnicos voluntarios de los BSL-2 y 3. Las entrevistas, con una duración de 30 a 90 minutos, fueron grabadas con el acuerdo de los participantes y siguieron un marco de referencia común que constó de seis temas:

- ¿En qué consiste la profesión, la actividad cotidiana y la organización del trabajo?

- La percepción de los recursos en el trabajo

- La percepción de las limitaciones en el trabajo

- La percepción de riesgo en el trabajo cotidiano

- La viabilidad de los procedimientos y de las prescripciones de seguridad

- La percepción del BSL-3 
Los recordatorios tuvieron como objetivo profundizar el discurso o centrarlo en los temas tratados.

Las entrevistas fueron transcritas manualmente en su totalidad, y las respuestas textuales fueron clasificadas manualmente por temas y subtemas, como aparece en el ejemplo a continuación.

Cuadro 1: Extracto del análisis temático de las entrevistas

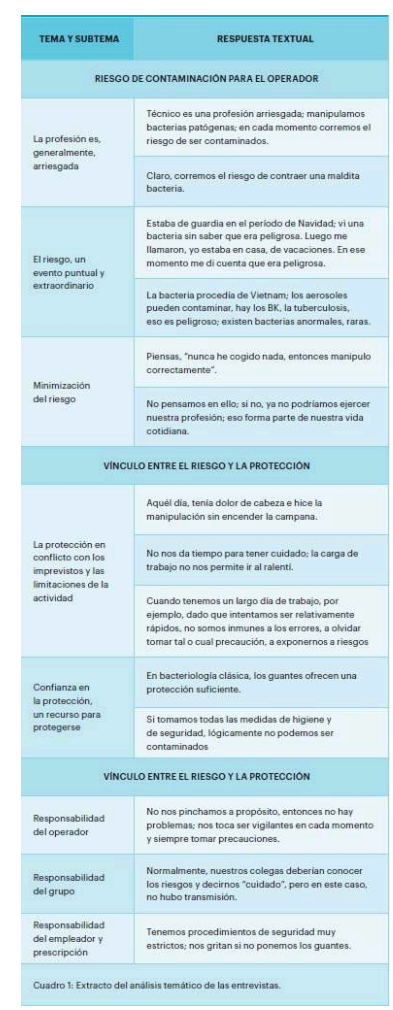

\section{2 - Observaciones}

79 Se realizaron observaciones abiertas y específicas. Estas observaciones específicas se centraron en el uso situado de los EPP y en la relación de los operadores con las prescripciones de seguridad: cómo su actividad responde a las prescripciones de seguridad y a su percepción de riesgo; y cómo ajustan las prescripciones en función de los imprevistos de su actividad. El objetivo es comprender lo que determina la aplicación, más o menos conforme, de las medidas de protección, en particular si algunas fuentes de variabilidad en su trabajo pueden influir en su propensión a protegerse. Esas observaciones se basaron en la actividad en los BSL-2 y 3. Para el BSL-3, las observaciones empezaron desde su puesta en servicio, y se realizaron de manera intermitente durante el primer año de actividad. Así, esta recopilación de información longitudinal permitió comprender cómo los operadores analizan y luego se apropian de las nuevas situaciones de trabajo.

80 Cada jornada de observación consistió en seguir a un operador desde el inicio hasta el final de su jornada laboral. Se tomaron apuntes sobre las acciones observadas y las verbalizaciones espontáneas de los operadores, los intercambios verbales entre ellos y las respuestas a los cuestionamientos del investigador en la práctica. 
Esas informaciones fueron inscritas en unas tablas reflejando los comportamientos de los operadores en relación con la seguridad, como se ve en el ejemplo siguiente.

Cuadro 2: Ejemplo de tabla de observación y de análisis

\begin{tabular}{|c|c|c|c|}
\hline SITUACION & USO DE LOS EPP & VERBALIZACION & ANALISIS \\
\hline \multirow{3}{*}{$\begin{array}{l}\text { EL OPERADOR EXPERIMENTADO } \\
\text { ADAPTA LA PRESCRIPCION EN } \\
\text { FUNCION DE SU PERCEPCION DE } \\
\text { LA LIMPIEZA O SUCIEDAD DE LAS } \\
\text { MUESTRAS. }\end{array}$} & La aprendiz usa guantes. & $\begin{array}{l}\text { En esta sala, hay que usar guantes } \\
\text { porque manipulamos muestras } \\
\text { muy variadas y nunca se sabe lo } \\
\text { que podemos encontrar. }\end{array}$ & $\begin{array}{l}\text { El operador sin experiencia sigue } \\
\text { la prescripción. }\end{array}$ \\
\hline & La técnica no usa guantes. & $\begin{array}{l}\text { Estoy acostumbrada a trabajar sin } \\
\text { guantes, no tengo cortes en las } \\
\text { manos; siempre tengo cuidado. }\end{array}$ & \multirow{2}{*}{$\begin{array}{l}\text { El operador experimentado } \\
\text { adapta la prescripción en función } \\
\text { de su percepoión de la limpiezao } \\
\text { suciedad de las muestras. }\end{array}$} \\
\hline & $\begin{array}{l}\text { La técnica se pone guantes en } \\
\text { medio de la secuencia. }\end{array}$ & $\begin{array}{l}\text { Pregurta del investigador: } 2 p \text { cr quẻ } \\
\text { usted se pone los guantes ahora? }\end{array}$ & \\
\hline \multirow{2}{*}{$\begin{array}{l}\text { UNA TECNICA ORDENA LAS } \\
\text { CA IAS (MEDIOS DE CULTIVO) EN } \\
\text { TRES PILAS: } \\
\text { - LAS CAUAS POSITIVAS } \\
\text { (UNA O DOS BACTERIAS } \\
\text { HAN CRECIDO, HABRA QUE } \\
\text { IDENTIFICARLAS), } \\
\text { LAS CAIAS NEGATIVAS (NO } \\
\text { HA CRECIDO NINGUNA } \\
\text { BACTERIA). } \\
\text { LAS FLORAS (HAN CRECIDO } \\
\text { MAS DE } 2 \text { BACTERIAS } \\
\text { DIFERENTES). }\end{array}$} & & $\begin{array}{l}\text { Esto es Clostridium, tiene un } \\
\text { olor peculiar, se huele cuando se } \\
\text { abre la caja. El pio huele también. } \\
\text { pero huele bastante bien, huele } \\
\text { a jazmin.. }\end{array}$ & \multirow{3}{*}{$\begin{array}{l}\text { El operador utiliza su sentido del } \\
\text { olfato para obtener informaciones } \\
\text { sobre el tipo de bacteris antes de } \\
\text { identificarla con el microscopio. } \\
\text { Adapta esta estrategia según su } \\
\text { percepción del carácter peligroso } \\
\text { de la muestra (en este caso, } \\
\text { segun la procedencia geográfica) }\end{array}$} \\
\hline & & $\begin{array}{l}\text { Pregunta del investigador: ¿no es } \\
\text { peligroso oler las cajas de cultivos? }\end{array}$ & \\
\hline $\begin{array}{l}\text { MAS DE } 2 \text { BACTERIAS } \\
\text { DIFERENTES). } \\
\text { ABRE UNA CAJA POSITIVA PARA } \\
\text { SENTIR SU OLOR. }\end{array}$ & & $\begin{array}{l}\text { No, la bacteria no es peligrosa; no } \\
\text { salta y tampoco se contrae por } \\
\text { inhalación. Pero las bacterias que } \\
\text { provienen del extranjero pueden } \\
\text { ser peligrosas; tuvimos una en } \\
\text { diciembre. }\end{array}$ & \\
\hline
\end{tabular}

\section{2 - Autoconfrontación}

El método llamado autoconfrontación cruzada (Clot, Faïta, Fernandez \& Scheller, 2000) fue implementado para permitir los debates sobre la actividad. Se trata de confrontar a un grupo de operadores con unas secuencias filmadas de su actividad laboral, para luego debatir sobre las diferencias de práctica. Los operadores fueron filmados durante unas secuencias específicas de su actividad; estas secuencias fueron elegidas por el riesgo que presentan. Con el acuerdo de los operadores, los vídeos fueron proyectados ante el grupo, y las diferentes prácticas fueron comentadas y debatidas.

En el caso presente, los técnicos del BSL-3 pudieron discutir con los dos biólogos sobre los conflictos entre los requisitos de trabajo y de seguridad, y su propia comodidad.

Este método, en relación con la particularidad de su uso y del contexto, fue adaptado para confrontar el prescriptor de las normas de seguridad con la aplicación de su prescripción. Concretamente, el prescriptor de las normas de seguridad (el jefe de laboratorio), fue filmado mientras ejecutaba sus propias prescripciones, incluso el uso de los EPP en situación real, como si fuera un operador. Este método sirvió para comprobar la viabilidad de las prescripciones de seguridad, habida cuenta de las limitaciones y posibilidades reales de la situación: la configuración de los locales, el equipo, el tiempo disponible, los imprevistos...Así, esta técnica se sitúa a medio camino entre una simulación y una autoconfrontación. Proyectando las secuencias filmadas ante el grupo, fue posible identificar y debatir los conflictos de criterios. 


\section{F) Descripción de la actividad y de los EPP} etapas principales:

Antes de abordar el tema de los resultados, las tareas de los técnicos serán descritas brevemente, así como los EPP usados, con un objetivo de comprensión e ilustración.

\section{1 - Descripción de la actividad}

El examen bacteriológico es un elemento central en la evaluación diagnóstica y terapéutica de la tuberculosis. Efectivamente, la identificación del BK en las muestras de esputo del enfermo va a confirmar la sospecha de tuberculosis, ella misma ya evocada a través del examen clínico y radiológico. Así pues, este examen bacteriológico supone un trabajo en un BSL-3, en particular el cultivo de la bacteria, con muestras potencialmente contaminadas.

Las tareas de los técnicos en relación con la búsqueda de los BK se estructuran en siete

1. Descontaminación de las muestras recibidas (en la CSM)

Las muestras son puestas en contacto con sosa durante veinte minutos, y luego son neutralizadas mediante una solución tampón. Los BK poseen, en efecto, la propiedad de ser bacilos ácido-alcohol resistentes (BAAR), a diferencia de las otras bacterias que son destruidas por la sosa. En esta etapa de descontaminación, se trata de eliminar las bacterias distintas a los BK para evitar una alteración de los resultados.

2. Frotis sobre un portaobjetos y tinción con auramina (en la CSM)

Se extiende una gota de la muestra descontaminada sobre un portaobjetos instalado sobre una placa calefactora por adición de alcohol. Así, el portaobjetos se tiñe con auramina en un teñidor automático.

3. Lectura del portaobjetos con el microscopio: examen directo (sala de microscopios)

Esta tinción permite observar la aparición de los BK por fluorescencia cuando son examinados con el microscopio en una sala oscura. Se trata del examen directo: la lectura del portaobjetos sirve para determinar si éste es positivo (presencia de BK) o negativo (ausencia de BK). Además, el examen directo tiene por objeto determinar el nivel de contaminación del enfermo, que depende de la densidad de bacilos presentes en los esputos del paciente. Este examen puede ser completado en un día, para que los servicios clínicos que lo solicitaron puedan decidir aislar o no al paciente. Sin embargo, el examen directo genera una tasa considerable de falsos negativos; es decir que la ausencia de BK con el examen directo no significa que el enfermo no está infectado con el bacilo. En el mejor de los casos, sabemos que el enfermo es poco contagioso.

4. Siembra y cultivo (en la CSM)

Para realizar el diagnóstico con certeza, se debe cultivar la muestra. Para ello, se introducen gotas de la muestra descontaminada en tubos que contienen reactivos, y éstos permiten la multiplicación de la bacteria si está presente. Se realizan simultáneamente dos tipos de cultivo, en medio sólido y en medio líquido; luego, los cultivos se ponen a incubar a 37 grados.

96 5. Examen de los cultivos (sala de cultivos) 
El BK siendo una bacteria de crecimiento lento, el cultivo dura varias semanas. Así, dos veces por semana, los técnicos examinan todos los cultivos sólidos para ver si unos BK han crecido en los tubos. El potencial desarrollo de unos BK en los cultivos líquidos es identificado por la incubadora automática, que señala los tubos "positivos" en tiempo real.

6. Frotis sobre un portaobjetos y tinción de Ziehl (en la CSM)

Si los cultivos son positivos, es decir que el BK se ha multiplicado en uno u otro de los medios de cultivo, habrá que identificarlo. Los técnicos efectúan un nuevo frotis sobre el portaobjetos, pero esta vez a partir de las bacterias puras y no de la muestra. Se realiza una tinción diferente (tinción de "Ziehl") y, otra vez, los portaobjetos son examinados bajo un microscopio.

7. Siembra de antibiogramas (en la CSM)

Después de identificar el BK, es necesario determinar el mejor tratamiento antibiótico para el paciente gracias al método del antibiograma. Este método permite medir la sensibilidad o la resistencia de un bacilo a los diferentes antibióticos. El objetivo es poner la bacteria cultivada en contacto con los principales antibióticos, y observar si es destruida o se desarrolla a pesar del antibiótico.

En paralelo, se realizan unas pruebas "rápidas" y otras de biología molecular. No se detallarán estas etapas en el presente artículo.

\section{2- Descripción de los EPP}

03 Los EPP que se deben utilizar en el recinto del BSL-3 incluyen una vestimenta específica, así como guantes, gafas, una mascarilla, cubrebotas y polainas. Además, durante las manipulaciones en la CSM, un segundo par de guantes y mangas desechables se deben usar en las etapas 1, 2, 4, 6 y 7 mencionadas anteriormente.

4 Una prescripción dicta la manera de poner y quitar los EPP: fuera del BSL-3, los operadores deben quitar su prenda personal y usar una bata de algodón. El calzado de calle es reemplazado por zuecos de plástico.

En la esclusa de vestir, los operadores dejan estos zuecos en la parte exterior de la esclusa y se ponen otro par de zuecos en la parte interior de la esclusa. Luego se ponen un mono de protección, una mascarilla de tipo "FFP2" y gafas de protección. Por encima de los zuecos van los cubrebotas y luego las polainas. Por fin, antes de entrar en el laboratorio, los operadores se ponen un cubrebata y un primer par de guantes de látex. 
Figura 1: Equipos de protección personal usados por los operadores dentro del BSL-3. Los elementos marcados en verde son de uso único, los otros son reutilizables.

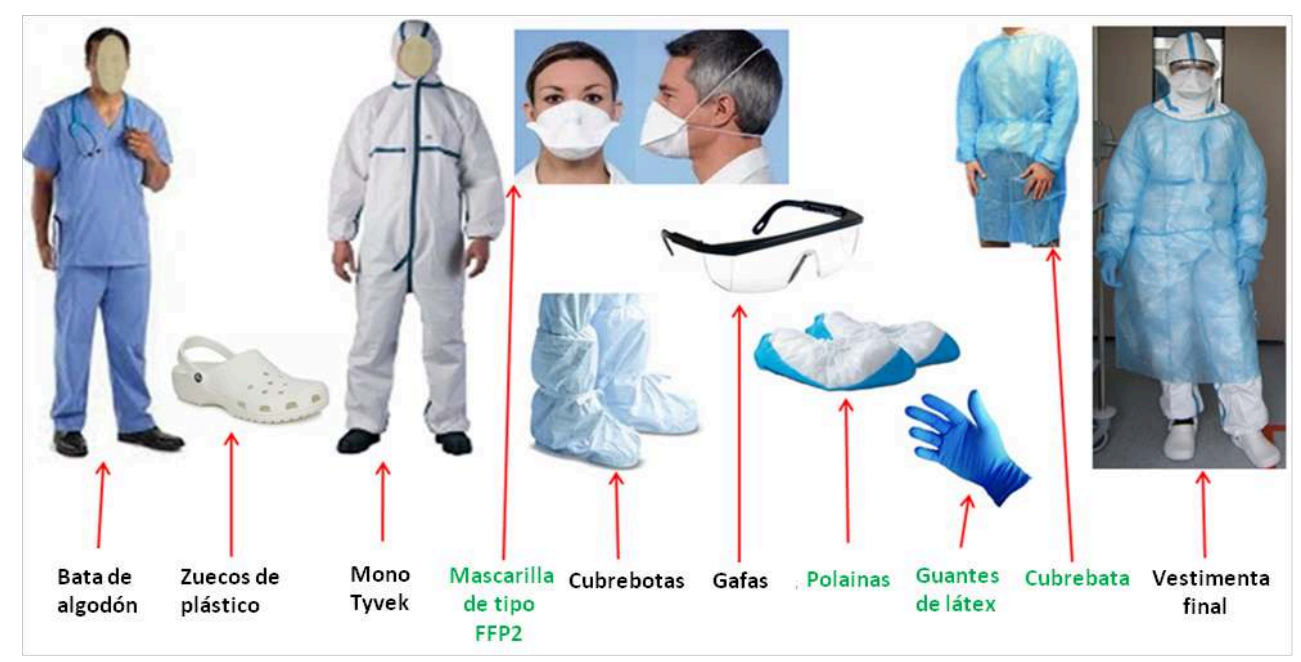

\section{G) Resultados: análisis del uso de los EPP}

Esta parte del artículo se centrará en el análisis de los vínculos entre las percepciones y las conductas respecto a los riesgos, y luego en los impactos del uso de los EPP sobre los operadores y las estrategias implementadas. Esto permitirá observar cómo los EPP interactúan con la actividad laboral.

\section{1 - Construcción / modificación de las percepciones de riesgo y relación con las prácticas}

107 Las entrevistas individuales y los intercambios durante las observaciones y reuniones han permitido identificar unas percepciones específicas respecto a los riesgos. Si algunas percepciones se expresan a través de las verbalizaciones de los operadores, otras se evidencian en las prácticas. Estas representaciones se construyen en parte de manera individual, y en parte de manera colectiva.

Por ejemplo, parece que algunas percepciones anteriores a la confrontación con una situación de riesgo orientan las prácticas. Luego, el compromiso en estas prácticas va a modificar las percepciones de los operadores. La retroalimentación ("feedbacks") recibida por los operadores va a entrañar estos cambios de percepción: retroalimentación en cuanto a sus acciones y retroalimentación resultante de los debates dentro del grupo.

De este modo, cada uno de los operadores puede empezar su actividad laboral en el laboratorio con su propio bagaje de experiencia. Sus percepciones se determinan según sus experiencias pasadas, su nivel de conocimientos y su propia sensibilidad.

\section{a - La percepción del peligro y la falta de experiencia resultan en un riguroso seguimiento de los procedimientos}

110 Los residuos procedentes del BSL-3 deben ser descontaminados mediante un ciclo de descontaminación por autoclave, para que las bacterias no se propaguen en el entorno. 
La autoclave descontamina los residuos produciendo una presión que permite calentar el vapor de agua hasta más de 100 grados, para esterilizar los residuos antes de la evacuación de los mismos. Esta herramienta no se utiliza en un BSL-2, y por consiguiente los operadores sin experiencia que trabajan en un BSL-3 nunca han llegado a utilizar uno. Por ejemplo, un operador decía, antes de empezar a trabajar en el BSL-3, que tenía miedo del entorno técnico de este laboratorio y en particular de la autoclave, una herramienta que nunca había utilizado antes.

111 Consideraba que "la autoclave es como una bomba, puede explotar", y expresaba sus preocupaciones respecto a la manipulación de la misma, a pesar de los entrenamientos que efectuó. Esta percepción determinó dos estrategias específicas, teniendo por objeto conferir la máxima seguridad en la manipulación de esta herramienta percibida como peligrosa: por una parte, el operador intentó seguir lo mejor posible las consignas prescritas, y por otra parte solicitó el apoyo de colegas o expertos para manipular la autoclave sin correr ningún riesgo. El objeto de estas dos estrategias era conseguir un uso seguro del instrumento, y también tranquilizarse.

Después de unos pocos meses de uso diario sin ningún accidente, la manipulación de la autoclave provoca menos ansiedad. Los operadores consideran que han desarrollado su habilidad en utilizarla y que el riesgo está controlado. En este caso, la confrontación con la práctica y la experiencia acumulada han modificado la percepción de riesgo.

\section{b - Percepción ampliada de riesgo para comprometerse al uso de los EPP}

113 Algunas estrategias cognitivas han surgido dentro del grupo, lo que indica que estas percepciones compartidas permiten asegurar la actividad tanto como estructuran este grupo. En este caso, el contenido de la percepción da lugar a una mayor seguridad.

114 Los técnicos saben que en caso de que surja una grave epidemia en Francia, podrían llegar a trabajar con organismos aún más peligrosos que la tuberculosis. En particular, la apertura del BSL-3 coincidió con un periodo de gran preocupación social vinculada con el virus del Ébola (que pertenece a la clase de peligrosidad máxima, el grupo 4 [6]). Alentados por el personal directivo, los operadores han desarrollado una estrategia mental que se puede resumir con esta frase: "quien puede lo más, puede lo menos". Entonces se han obligado a adoptar las más altas medidas de seguridad respecto al riesgo real, considerando que en caso necesario, se habrán acostumbrado a protegerse. Esta situación se puede comparar con un entrenamiento militar: uno tiene que estar siempre preparado para lo peor, en caso de necesidad.

115 Estas percepciones aún persisten más de un año después de la apertura del laboratorio. Para mantener su vigilancia, los operadores dicen que imaginan que cada gota de muestra contiene unos BK.

116 Por ello, esta estrategia espontánea permite compensar la falta de experiencia y acompañar el cambio de costumbre en comparación con la actividad en el BSL-2. Todo indica que esta percepción, alejada de la realidad, lleva a los operadores a dar sentido y entonces soportar mejor las limitaciones de los EPP. Parece que la percepción del miedo a la contaminación permite relativizar la incomodidad de los EPP. 


\section{c - El grupo como medio de asegurar las prácticas}

117 A nivel del grupo, las percepciones tienen un impacto sobre las prácticas implementadas espontáneamente por los individuos: a veces los operadores se observan los unos a los otros para rectificar los gestos que no sean conformes a su visión común de la seguridad. Así, el trabajo colectivo se convierte en un recurso para la seguridad.

118 Además, los operadores pueden comparar sus puntos de vista sobre aspectos que escapan a las prescripciones, por ejemplo la realización de ciertos gestos específicos. En particular, en lo que concierne a la manera de manipular la tapa de un tubo para no entrar en contacto con su contenido, coexistían dos opciones dentro del grupo. Algunos operadores depositaban la tapa en la superficie de la mesa durante la punción del contenido del tubo, mientras otros mantenían la tapa entre el meñique y la palma de la mano porque pensaban que existía un riesgo, incluso mínimo, de fuga de líquido en la mesa si se depositaba la tapa en la misma. Este gesto permite evitar depositar la tapa en la mesa durante la toma de muestra del tubo. Comparando sus percepciones de riesgo respectivas, los operadores decidieron adoptar colectivamente la práctica conforme a la exigencia de no contaminación: mantener la tapa.

\section{d-Percepción errónea que puede resultar en el incumplimiento de la prescripción}

119 En paralelo, existen percepciones erróneas en cuanto a un aspecto del riesgo biológico, en particular el modo de transmisión de la bacteria. Esta percepción proviene de la experiencia anterior de los operadores con otros tipos de bacterias que presentan unos modos de contaminación diferentes (especialmente por vía cutánea o transcutánea). En este caso existe un desfase persistente entre los conocimientos relativos a la transmisión del BK y una percepción de riesgo resultante de las experiencias previas.

120 Así, en cuanto a los EPP, los técnicos tienden a privilegiar los guantes en detrimento de la mascarilla en la sala de lectura de los portaobjetos con el microscopio. Se reconoce que esta sala presenta un riesgo muy bajo, porque los portaobjetos se limpian con alcohol. Aunque los portaobjetos contuvieran unos BK, éstos están fijados y no son contagiosos. Entonces, aunque no es necesario usar guantes y aunque el único EPP que puede ofrecer un interés es la mascarilla, los operadores prefieren los guantes y ahorrarse el uso de la mascarilla. Admiten la superfluidad de los guantes pero explican que "nunca se sabe...".

121 A nivel de los modos operativos, los técnicos solían depositar la tapa de un frasco en la superficie de trabajo con la abertura hacia arriba. En los otros tipos de laboratorio, esto tiene la ventaja de evitar que el contorno de la tapa esté en contacto con la superficie de trabajo, para no contaminarla. Pero una lógica inversa prevalece en el trabajo con los BK; dado que estas bacterias se propagan por vía aérea, resulta mejor depositar la tapa con la abertura hacia abajo para atrapar los eventuales BK entre la tapa y la superficie de trabajo, esta última siendo descontaminada después de cada sesión de trabajo. Al darse cuenta de esta lógica inversa, los técnicos adaptaron sus costumbres.

Así, se puede considerar que los conocimientos contenidos en las percepciones orientan las prácticas iniciales, de la misma manera que las prácticas implementadas influyen a su vez en las percepciones. 


\section{2 - Los impactos de los EPP sobre los operadores}


Una limitación fuerte se compensa con una gran utilidad percibida. Otros equipos, como la mascarilla, son menos usuales porque no se usan en otros laboratorios que en un BSL-3. Pero habida cuenta de su absoluta necesidad en cuanto al riesgo (los BK se propagan por vía aérea), los técnicos tienen realmente cuidado de usarla en todas las situaciones potencialmente arriesgadas.

Por fin, una limitación asociada a una percepción de escasa utilidad lleva a los operadores a renunciar al uso del equipo. Esto ocurre con las gafas de protección: según la morfología del rostro, pueden quedar demasiado apretadas y provocar puntos de presión, deslizarse o empañarse. Los operadores que perciben esta molestia tienden a no usarlas.

\section{b - Compromiso a través de un uso adaptado de los EPP}

134 El compromiso consiste en adaptar el uso de los EPP a las circunstancias. Por ejemplo, se pueden usar sin seguir completamente las instrucciones de uso. Así, una bata o cubrebata se puede usar sin estar cerrada, o el mono sin la capucha puesta. Con esta estrategia se trata de aceptar el uso de los equipos, evitando parte de sus inconvenientes. Las gafas se pueden llevar en la cabeza y no en la nariz, para usarlas en ciertos momentos críticos y no de manera permanente.

En otro laboratorio, unas observaciones han permitido constatar que estos compromisos se pueden aplicar también a los equipos de protección colectivos. Así, los operadores pueden trabajar bajo una campana extractora encendida; no trabajan en una superficie de trabajo simple y aceptan la limitación de un espacio reducido bajo la campana. Pero no utilizan la función extractora de la campana para no sufrir la molestia del ruido de ventilación. Este tipo de estrategia plantea preguntas y representa una importante asunción de riesgos. Efectivamente, los equipos utilizados de una manera "inapropiada" tienen una capacidad de protección casi nula mientras el operador parece, o incluso se siente, protegido.

\section{c-Desarrollo de recursos colectivos para la seguridad}

La aparición y la discusión sobre las percepciones relacionadas con el riesgo y la actividad representan una creación de recursos para el grupo y para el resultado del trabajo. Así, como complemento de las prescripciones, los operadores desarrollan por sí mismos unas estrategias para garantizar su seguridad.

Armonizando su percepción de la "manera correcta" de trabajar, hasta en los más mínimos detalles, saben que "se puede seguir con la tarea de un colega en cualquier momento", tanto a nivel de la actividad como de la seguridad.

Para favorecer el trabajo colectivo, han desarrollado modos operativos que permiten comprender el progreso del trabajo de un colega: por ejemplo, suelen desplazar los tubos de una casilla hacia la derecha en el soporte para diferenciar los tubos examinados de los otros. Asimismo, otra norma compartida por los operadores consiste en eliminar los residuos de la superficie de trabajo después de cada secuencia, guardar los instrumentos y descontaminar el plano de trabajo bajo la campana. De esta forma, saben que el espacio de trabajo está "limpio" y no presenta riesgos de contener unos BK. En caso de que un operador no respete esta norma del grupo, sus colegas se niegan 
a relevarle: "si la mesa no está ordenada, no parece limpia y no se sabe si quedan BK o no; yo no la toco".

139 Así, se puede comprobar que el uso de ciertos equipos de protección queda en parte determinado por la situación de trabajo en la que interviene y que, a su vez, este uso tiene impactos sobre la actividad real.

\section{6 - Los impactos de los EPP sobre la actividad}

140 Más allá de las molestias que causan al individuo, los EPP también pueden representar una limitación para la actividad en la que se usan.

141 Esto obliga a los operadores a implementar nuevas estrategias de control y nuevos modos operativos. Sin embargo se debe mencionar que, paradójicamente, los EPP pueden ocasionar otros problemas de seguridad o incluso resultar contraproducentes en ciertas circunstancias.

\section{a - Uso limitante para la actividad}

142 Esta molestia para la actividad puede repercutir de distintas formas en los determinantes o en los resultados de la actividad. Algunos EPP pueden desestabilizar el funcionamiento del grupo, especialmente complicando la comunicación. Por ejemplo la mascarilla afecta los intercambios verbales; dado que resulta más fatigante hablar con una mascarilla puesta, los intercambios son más específicos y entonces menos numerosos o más breves. Así pues, la actividad requiere que los operadores hablen entre sí: informar que se ha encontrado un tubo positivo, que se necesita algún equipo. La comunicación no verbal también se ve afectada: no se pueden percibir todas las expresiones del rostro detrás de una mascarilla.

143 A nivel de los procesos de trabajo, las limitaciones relacionadas con el uso de los EPP implican prescripciones adicionales: usar un segundo par de guantes para trabajar bajo la campana, pensar en quitarse las polainas y la cubrebata al entrar en la sala de microscopios, recordar el orden en que se tienen que poner y quitar los distintos EPP. Esto puede añadir una carga cognitiva a las informaciones a retener para realizar el trabajo.

144 Además, los EPP pueden impactar en los resultados del trabajo, especialmente en términos de rapidez de realización o de precisión de las manipulaciones. Sin embargo, se pueden superar si los operadores consiguen adaptarse. Esto tiene que ver con el “proceso de instrumentación", un concepto desarrollado por Rabardel (1995, p. 111) en el sentido de que el operador va a adaptar su manera de utilizar un "instrumento", según un proceso de adaptación o de asimilación dentro de unos esquemas existentes.

\section{b - Readaptación de las prescripciones a la actividad}

145 A otro nivel, las prescripciones de uso y utilización de los EPP, incluyendo el vestirse y el desvestirse, pueden ser inadaptadas con respecto a ciertos determinantes de la actividad. En algunos casos, resulta complicado o imposible para el operador adaptarse él mismo, y tenderá a adaptar la prescripción o la manera de utilizar los EPP. Nos acercamos entonces al "proceso de instrumentalización" de las herramientas según Rabardel (1995). 
Consideremos los determinantes espaciales que pueden entrar en conflicto con las prescripciones de seguridad. Por ejemplo, la esclusa donde los operadores se visten es muy pequeña. Además en este espacio, un marcaje en el suelo separa la "zona limpia" de la "zona sucia". La prescripción es la siguiente: los EPP reutilizables y que hayan entrado en el BSL-3 deben imperativamente permanecer en la "zona sucia", mientras que cualquier objeto que todavía no haya entrado en el BSL-3 debe permanecer en la "zona limpia". Así pues, filmando a los operadores y al prescriptor vistiéndose o desvistiéndose, se vio que era imposible para ellos no pasar la línea en la práctica, el espacio siendo demasiado limitado como para mantener su propio equilibrio en la zona. Las discusiones en grupos de trabajo han permitido modificar esta prescripción.

Estas prescripciones también pueden entrar en conflicto con unas exigencias de la actividad, como la obligación inicial de usar una mascarilla en todo momento en todas las salas del BSL-3. Los técnicos han observado y debatido el hecho de que la mascarilla perjudicaba la concentración necesaria para leer los portaobjetos con el microscopio en una sala oscura. Efectivamente, la realidad de esta actividad resulta muy costosa desde un punto de vista cognitivo: por una parte, se deben analizar un centenar de campos por portaobjetos, lo que significa dedicar aproximadamente tres minutos para cada portaobjetos; por otra parte, la finalidad de la acción es buscar activamente, y sin perder ninguno, los elementos fluorescentes evocando la forma de un BK. Pero unos elementos fluorescentes también pueden aparecer en el caso de trozos de célula y no de BK; entonces, se debe conseguir diferenciar los unos de los otros. Además de la carga atencional necesaria para leer de 20 a 30 portaobjetos seguidos y del esfuerzo para los ojos, esta etapa de la actividad implica un fuerte reto: los operadores saben que la decisión de aislar o no el paciente depende de su capacidad para lograr un buen resultado. Por consiguiente, una implicación subjetiva existe en esta acción. Por supuesto, en caso de duda, pueden buscar ayuda de los colegas o del biólogo.

Todos estos elementos hacen fastidiosa la lectura de los portaobjetos. Siendo la última de la secuencia, esta tarea interviene al final de la jornada y los técnicos deben satisfacer la prescripción de productividad relacionada con el compromiso del BSL-3 con el solicitante del análisis: el resultado del examen directo se debe proporcionar el mismo día, para todas las muestras recibidas a más tardar a las 09h30 de la mañana. Esta prescripción tiene en cuenta las limitaciones relacionadas con el cuidado del paciente, antes de las debidas a los imprevistos encontrados en el laboratorio: variabilidad del número de muestras, complejidad de los casos, averías de los autómatas, agotamiento de existencias de material, ausencias de los operadores, casos de no conformidad en el registro...En vista de la importancia del cuidado del paciente, la productividad y la fiabilidad de los resultados dependen de los operadores.

Discutiendo esta problemática colectivamente con el prescriptor, y habida cuenta del riesgo real de contaminación muy bajo en la sala de microscopios, la prescripción de uso de la mascarilla ha sido adaptada a la situación, y resulta que usar la mascarilla ya no es obligatorio en esta sala.

\section{B) Discusión}

Estos resultados destacan la importancia de replantear los EPP en un concepto más amplio de la seguridad. Aunque forman parte integrante de las medidas de seguridad, 
los EPP pueden y deben ser objetos de debates colectivos, basándose en la actividad real.

Parece inevitable realizar un trabajo sobre la actividad real, especialmente sobre la posición del riesgo (real y percibido) en conexión con las prescripciones relativas a los EPP y los otros determinantes de la actividad laboral en situaciones de riesgo biológico.

Así, los métodos clásicos de análisis de la actividad pueden permitir centrar los debates en estas prescripciones de seguridad. Parece necesario contar con cierto margen de maniobra para adaptar tanto las regulaciones de la actividad (tiempo de apropiación, intercambios de prácticas), como la prescripción cuando sea posible. Efectivamente, unas prescripciones excesivamente restrictivas para los operadores o su actividad pueden ser desviadas o abandonadas en la práctica.

Estos resultados animan a los operadores a que consideren las percepciones de riesgo como determinantes de pleno derecho de la actividad, en la medida en que prescriben ciertos comportamientos, sobre todo cuando una prescripción organizacional no resulta suficientemente precisa.

El recurso constituido por el grupo es un elemento central de la seguridad. Así, desde el principio de la nueva actividad, cada semana en las reuniones de equipo los operadores han podido informar sobre los nuevos interrogantes que hayan surgido durante su experiencia en una situación real.

El desarrollo de este recurso requiere una gerencia a la escucha de los comentarios de los operadores. Aquí, la capacidad de escucha del jefe de laboratorio ha sido un determinante decisivo en la construcción de una cultura de confianza en cuanto a la seguridad: las desviaciones de conducta relacionadas con la seguridad han sido debatidas y no sancionadas.

El método de autoconfrontación cruzada ha permitido un debate detallado sobre las etapas complejas de la actividad que presentan un riesgo para la fiabilidad de los resultados o la seguridad de los operadores. El uso de las secuencias filmadas ha permitido centrar el debate en la actividad y sus paradojas. Se han probado sucesivamente varias soluciones alternativas, para definir colectivamente las normas de lo que es aceptable o no lo es en términos de procedimientos de trabajo o de toma de riesgos.

En cuanto a los límites, cabe destacar la dificultad para sistematizar los resultados obtenidos, en vista de la dotación de personal muy reducida. A la luz de los métodos implementados, algunos operadores han señalado el malestar que a veces sienten al ver su actividad expuesta ante el equipo, a pesar del recordatorio de los objetivos de los métodos empleados. Esto refuerza la importancia de explicar en detalle los métodos de análisis de la actividad utilizados en la psicología del trabajo y en la ergonomía de la actividad.

\section{C) Conclusión}

158 Este artículo tenía como objetivo mostrar que más allá de la aceptabilidad intrínseca de un EPP, es la atención que se presta a su uso en la actividad laboral que determinará su utilización. Efectivamente, el uso de los EPP y más ampliamente de los instrumentos en el trabajo, así como la actividad de reinterpretación de las prescripciones, siempre movilizarán la inteligencia de los operadores y su capacidad para adaptar 
recíprocamente los EPP y los determinantes de la actividad. El objetivo era también mostrar la importancia de la esfera representacional en la gestión de la seguridad. En la medida en que existe una influencia recíproca entre las percepciones y las prácticas, se puede utilizar esta dinámica para buscar una coherencia que traiga más seguridad en el trabajo.

Entonces, esta búsqueda consistía en proponer algunos medios para ajustar recíprocamente los EPP a la actividad en situación de riesgo, con el fin de encontrar un compromiso entre la búsqueda de productividad, de seguridad y de comodidad de los operadores.

Por lo tanto, un método de intervención que favorezca los debates sobre la actividad real, tomando en cuenta las percepciones, parece necesario para que las acciones de prevención de riesgos en sentido amplio sean eficaces.

\section{BIBLIOGRAFÍA}

Abric, J.C. (1994). Pratiques sociales et représentations. Paris: PUF.

Antoine, D., \& Che, D. (2012). Les cas de tuberculose déclarés en France en 2010. Bulletin Epidémiologique Hebdomadaire de l'Institut de Veille Sanitaire. Numéro thématique: Tuberculose en France: la vigilance reste nécessaire, 24-25.

Cadet, B., \& Kouabénan, D.R. (2005). Évaluer et modéliser les risques: apports et limites de différents paradigmes dans le diagnostic de sécurité. Le travail humain, 68(1), 7-35.

Caroly, S., Simonet, P., \& Vézina, N. (2015) Marge de manœuvre et pouvoir d'agir dans la prévention des TMS et des RPS. Le travail humain, 78(1).

Clot, Y., Faïta, D., Fernandez, G., \& Scheller, L. (2000). Entretiens en auto-confrontation croisée: une méthode en clinique de l'activité. Perspectives interdisciplinaires sur le travail et la santé, 2(1).

Clot, Y. (2000). La fonction psychologique du collectif. In: T.H Benchekroun \& A. Weill-Fassina (Coord.), Le travail collectif: perspectives actuelles en ergonomie (pp.272-286). Toulouse: Editions Octarès.

Clot, Y. (2010). Le travail à cœur. Pour en finir avec les risques psychosociaux, Paris: La Découverte.

CNRS (2014) Risque biologique. Les cahiers de prévention Santé Sécurité Environnement.

Daniellou, F. (2002). Le travail des prescriptions. Conférence inaugurale, Actes du $17^{\mathrm{e}}$ congrès de la SELF, Aix en Provence.

Daniellou, F., Simard, M. \& Boissières, I (2010). Facteurs humains et organisationnels de la sécurité industrielle: un état de l'art. Cahiers de la sécurité industrielle, 2010(02), Fondation pour une culture de sécurité industrielle, Toulouse. 
Davillerd, C. (2001). Prévention et port des équipements de protection individuelle: 6 . Un centre hospitalier: L'application des prescriptions de sécurité par le personnel infirmier. Les notes scientifiques et techniques de l'INRS, 215.

De la Garza, C. (1995). Gestions individuelles et collectives du danger et du risque dans la maintenance d'infrastructures ferroviaires. Thèse de doctorat en Ergonomie, Ecole Pratique des Hautes Etudes, Université Paris 5, Paris.

De la Garza, C., \& Weill-Fassina, A. (2000). Régulations horizontales et verticales du risque. In: T.H Benchekroun \& A. Weill-Fassina (Coord.), Le travail collectif: perspectives actuelles en ergonomie. Toulouse: Editions Octarès.

Delgoulet, C. (2010). Discussion générale. Dans Expérience professionnelle et gestion de la sécurité au travail Actes du séminaire Ages et Travail 2008. CREAPT-CEE, $\mathrm{N}^{\circ} 58$.

Francequin, G. (2008). Quand l'habit devient protection de la santé. In: G. Francequin, Le vêtement de travail, une deuxième peau, Toulouse: ERES, Sociologie clinique.

Garrigou, A. \& Le Frious, P. (2015). Les équipements individuels: protecteurs, mais pas toujours. In: A. Thébaud-Mony, P. Davezies, L. Vogel \& S. Volkoff (Eds), Les risques du travail. Pour ne pas perdre sa vie à la gagner. Paris: Editions La Découverte.

Hoc, J.M., Amalberti, R., Cellier, J.M., \& Grosjean, V. (2004). Adaptation et gestion des risques en situation dynamique. In: J.M. Hoc, \& F. Darses (Eds), Psychologie ergonomique: tendances actuelles. Paris: Presses Universitaires de France.

Inouye, (2014) Risk perception: Theories, strategies and next steps. National Safety Council, Campbell Institute, USA.

INRS (1999) Classement des agents biologiques. La revue pour le médecin de travail, Collection Textes Officiels. Référence INRS TO 1.

Kouabénan, D.R. (2006) Des croyances aux comportements de protection. In: D. R. Kouabénan, B. Cadet, D. Hermand \& M. T. Munos Sastre, Psychologie du risque. Identifier, évaluer, prévenir. Bruxelles: .Editions De Boeck Universités, Collection Ouvertures Psychologiques.

Le Breton, D. (2012) Sociologie du risque. Paris: Presses Universitaires de France, Collection Que Sais-je.

Leplat J. (2008). Repères pour l'analyse de l'activité en ergonomie, Paris: Presses Universitaires de France, Collection Le Travail Humain.

Leporc, E., Carré, N., \& Vandentorren, S. (2014). Evolution de la tuberculose en Ile de France de 2000 à 2010. Bulletin Epidémiologique Hebdomadaire, 8, 138-43.

Le Mab, G., Mannoni, C., Brebion, C., Vincenti, M., Filippi, L., Poisson-Gonzalez, ..., Debeugny, C. (2012) La tuberculose en Seine Saint Denis. Le Point en 2012. Service de Prévention et des Actions Sanitaires du Département de Seine Saint Denis.

Mohammed-Brahim, B. (2009) Travailler en présence de substances toxiques : un corps à corps au quotidien. Corps, 6(1), 53-59.

Nascimento, A., Cuvelier, L., Mollo, V., Dicioccio, A., \& Falzon, P. (2013). Construire la sécurité: du normatif à l'adaptatif. In: P. Falzon (Ed) Ergonomie constructive. PUF, Paris.

Rabardel, P. (1995). Les hommes et les technologies. Approches cognitives des instruments contemporains. Paris: Armand Colin. 
Setbon, M. (2004). Risques, sécurité sanitaire et processus de décision. Collection Médecine des risques, Paris: Elsevier.

Valléry, G. (2004). Relations de service et approche ergonomique: saisir le caractère dynamique et situé de l'activité au travers de l'analyse des interactions «agent-client », @ctivités, 1(2), 121-146.

Véziris, N., Jarlier, V., \& Robert, J. (2012). La résistance aux antituberculeux en France en 2009-2010. Bulletin Epidémiologique Hebdomadaire de l'Institut de Veille Sanitaire. Numéro thématique: Tuberculose en France: la vigilance reste nécessaire, 24-25.

Vidal-Gomel, C. (2002). Systèmes d'instruments des opérateurs. Un point de vue pour analyser le rapport aux règles de sécurité. Perspectives interdisciplinaires sur le travail et la santé, 4(2). doi: 10.4000/pistes.3367.

Weill-Fassina, A. (2010). Evolutions de la gestion de la sécurité en situation de travail avec l'expérience professionnelle. In: Expérience professionnelle et gestion de la sécurité au travail Actes du séminaire Ages et Travail 2008. CREAPT-CEE, $\mathrm{N}^{\circ} 58$.

\section{NOTAS}

1. La incidencia de una enfermedad es el número de nuevos casos conocidos en una población en un momento determinado.

2. Observatorio Regional de Salud de Ile-de-France, 2013.

3. Norma de Seguridad Biológica de nivel 3.

4. "El grupo 2 incluye los agentes biológicos que puedan causar una enfermedad en el hombre y presenten un peligro para los trabajadores. Es poco probable que se propaguen a la colectividad y existen generalmente una profilaxis o un tratamiento eficaces". Artículo R-4421-3 del Código de Trabajo)

5. El FNP (Fondo Nacional de Prevención de los accidentes laborales y enfermedades profesionales) fue creado por el artículo 31 de la ley 2001-624 del 17 de julio de 2001. Componente del CNRACL (fondo nacional de pensiones de los agentes de las colectividades locales), el FNP está gestionado por la Caisse des Dépôts (Caja des Depósitos). El FNP está financiado por un gravamen sobre el producto de las contribuciones jubilatorias cobradas por el CNRACL.

6. "El grupo 4 incluye los agentes biológicos que puedan causar enfermedades graves en el hombre y presenten un peligro serio para los trabajadores. El riesgo de propagación a la colectividad es elevado.

\section{RESÚMENES}

Este artículo se centra en el uso de los EPP frente al riesgo biológico, basándose en una investigación-acción llevada a cabo dentro de un laboratorio de análisis biológico de contención de nivel 3 (o BSL-3, del inglés Biosafety Level 3). Los primeros resultados, procedentes del estudio de las percepciones de riesgo asociadas al análisis de la actividad, llevan a la conclusión de que el uso efectivo de los EPP se efectúa según los requisitos de seguridad y también el riesgo debido a la actividad, tal como lo perciben los operadores. Al mismo tiempo, en función de las limitaciones que los EPP pueden presentar en distintas situaciones, los operadores pueden adaptar su uso, e 
incluso aplicar estrategias complementarias para conciliar eficiencia y seguridad. Así, la búsqueda de seguridad necesita tomar en consideración a los EPP, dentro del marco más amplio de las relaciones entre los operadores, su percepción de riesgo y la actividad real

Este artigo centra-se no uso dos EPI face ao risco biológico, tendo como base uma investigaçãoação conduzida num laboratório de análise biológico de contenção de nível 3 (ou BSL-3, do inglês Biosafety Level 3). Os primeiros resultados, procedentes do estudo das perceções de risco associadas à análise de atividade, levam à conclusão de que o uso efetivo dos EPI é assumido de acordo com os requisitos de segurança prescritos e o risco induzido pela atividade, tal como é percebido pelos operadores. Ao mesmo tempo, em função das limitações que os EPI podem apresentar em situações distintas, os operadores podem adaptar o seu uso, e inclusive mobilizar estratégias complementares para conciliar eficiência e segurança. Assim, a procura de segurança requer considerar os EPI no contexto mais amplo das relações entre os operadores, a sua perceção de risco e a atividade real.

Cet article porte sur l'usage d'EPI face au risque biologique, en prenant appui sur une rechercheaction menée dans un laboratoire d'analyse biologique confiné de type «L3». Les premiers résultats, issus de l'étude des représentations du risque, associées à l'analyse de l'activité, amènent au constat que l'usage réel des EPI s'effectue selon la prescription de sécurité et selon le risque induit par l'activité, tel qu'il est perçu par les opérateurs. En même temps, selon les contraintes que les EPI occasionnent en situation, les opérateurs peuvent adapter l'usage qu'ils en font, voire mettre en œuvre des stratégies complémentaires pour concilier l'efficience et la sécurité dans l'activité. Ainsi, la recherche de sécurité nécessite de considérer les EPI dans le cadre élargi des rapports entre les opérateurs, leur représentation du risque et l'activité réelle.

This article focuses on the use of personal protective equipment (PPE) with regard to biological risk. It is based on an action research approach conducted in a confined biological analysis laboratory, of "class 3" safety level. The first results, coming from the analysis of risk perception and the operators' activity, show that their actual use of PPE depends on both the safety prescription and their own perception of risk in the work activity. At the same time, depending on the constraints caused by the PPE in situation, operators adjust the way they wear or use them, whilst implementing additional strategies to reach both efficiency and safety in the work activity. Thus, work safety in this context requires considering the PPE in a broader framework: the relation between operators, their risk perception and real work activity.

\section{ÍNDICE}

Keywords: Biological risk, Risk Perception, personal protective equipment, Activity, Safety Palabras claves: Riesgo biológico, Percepción de riesgo, Equipo de Protección Personal, Actividad, Seguridad

Palavras-chave: Risco biológico, Perceção de risco, Equipamentos de Proteção Individual, Atividade, Segurança

Mots-clés: Risque Biologique, Représentation du risque, Equipement de Protection Individuelle, Activité, Sécurité 


\section{AUTORES}

\section{SOFIANE DAHAK}

Equipe Travail, Situation et Organisation (TSO), Centre de Recherche en Psychologie : Cognition, Psychisme et Organisations (CRP-CPO), Université de Picardie Jules Verne (UPJV), Chemin du Thil, 80000 Amiens, France.

(1)irenacottin@gmail.com

(2)gerard.vallery@wanadoo.fr

(3)d_sofiane@live.fr 